\title{
Rangelands of Gobi Gurvan Saikhan National Conservation Park, Mongolia
}

\author{
Donald J. Bedunah and Sabine M. Schmidt
}

G obi Gurvan Saikhan National Conservation Park is an area of stark, natural beauty and an invaluable natural and cultural resource. To visit this area is much like going back in time with pastoralists herding their livestock with methods similar to Chinggis Khan's era. Snow leopards, wolves, argali, and Ibex still roam the mountains and thousands of gazelle graze the steppe. During the summer of 1998 we examined the park's rangelands and visited with the pastoralists almost daily gathering information for a conservation plan to benefit the park and the pastoralists utilizing the park.

\section{Park Overview}

Gobi Gurvan Saikhan National Conservation Park is one of Mongolia's 35 protected areas. It was established in 1993 on the recommendations of Mongolian conservationists and the World Wildlife Fund. The park is approximately 5.68 million acres or more than twice the size of Yellowstone National Park and is located in south central Mongolia in the Omnogobi aimag (Mongolia's 21 aimags are like states or provinces).

Since Mongolia passed its Protected Areas Law of 1994, the country has greatly expanded the amount of land with protected area designation; by late 1997 there were 39 million acres or about $11 \%$ of the country in protected areas. There are four types of protected area designations: Strictly Protected Areas, National Conservation Parks, Nature Reserves, and Monuments. Each is managed by the Protected Area Bureau within the Ministry of Nature and Environment, but each designation has its own restrictions concerning human use. Gobi Gurvan Saikhan National Conservation Park is one of 6 National Conservation Parks (NCP). These areas were designated as NCP because their natural condition is relatively intact and they have historic, cultural, scientific, educational, and ecological importance. By Mongolian law, the NCP are divided into three zones: a special use zone, a tourist zone, and a limited use zone. Livestock grazing is prohibited in the special use zone, but allowed in the limited use zones. Currently, it is ambiguous if livestock grazing will be permitted in the tourism zone. Gobi Gurvan Saikhan National Conservation Park has submitted a zonation proposal to the Mongolia Ministry of Environment for approval. The proposed special use zone where livestock grazing would be prohibited will be limited to very high elevations and areas that currently have very low grazing use (more extreme desert type). Currently the park is utilized by 1,100 herding households and over 218,000 head of livestock. Controlling grazing in these zones will be difficult because of political and social constraints, but the park administration has adopted a participatory approach toward management planning with local herders.

Gobi Gurvan Saikhan can be interpreted as the "Three Beauties of the Gobi" referring to the mountain ranges, Zuun Saikhan, Dund Saikhan, and Baruun Saikhan (East, Middle, and West Beauties) that rise above the dry steppe. Although the park is named for these mountain ranges, other spectacular

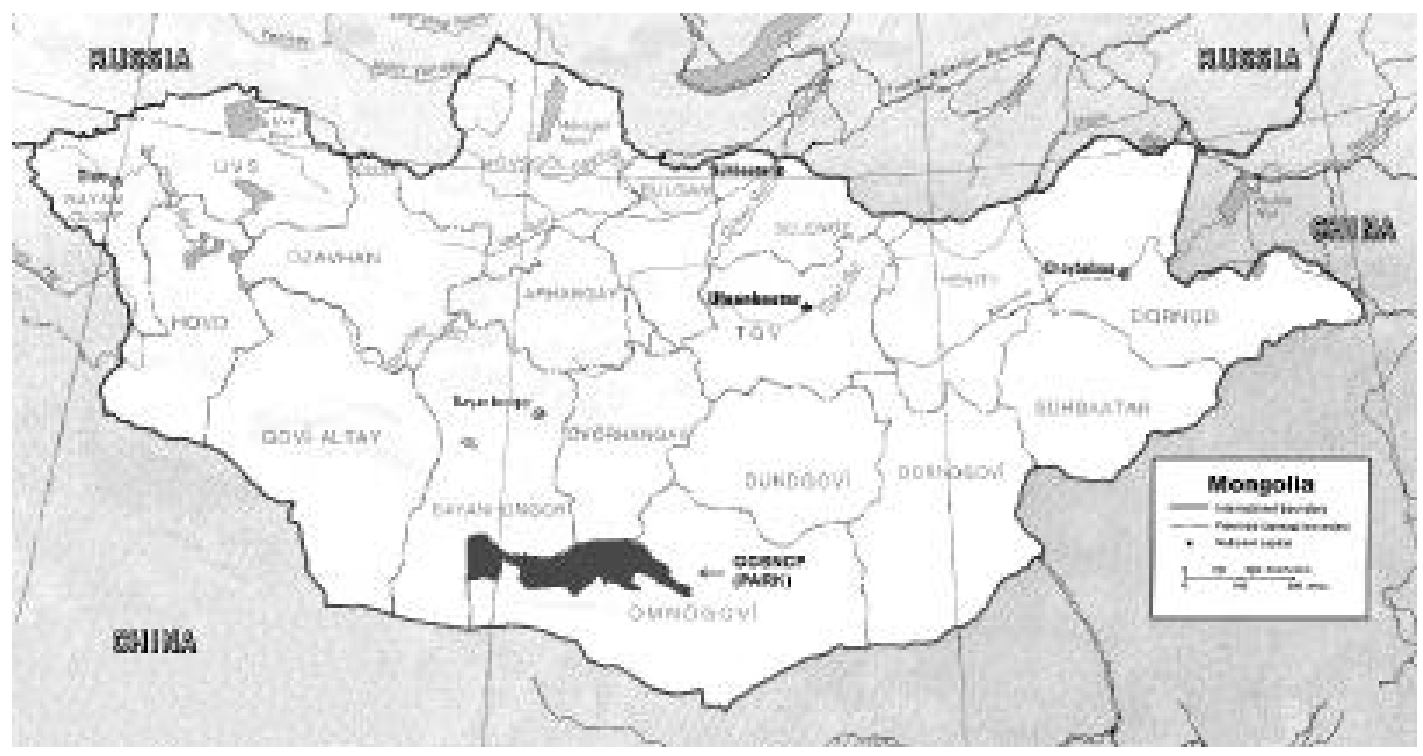

Mongolia, its aimags or provinces and the location of Gobi Gurvan Saikhan National Conservation Park (GGSNCP). 
mountain ranges within the park include Bayan Tsagaan, Zoolongiin, Sevrei, and the Nemegt Ranges. The Altan (Gold) Mountain, located just outside of the park, is an area of religious and biological importance and was certainly an area that conservationists and local peoples wanted as part of the park. This area was removed from the park to allow for the operation of a gold mine. However, there continues to be local support to protect this area from development. There are no paved highways in the region and few roads within the park. As the park is in its infancy there are few tourists in comparison to U.S. parks. However, this area has been one of the prime tourist destinations of Mongolia for several decades and tourist numbers continue to increase.

\section{Rangelands}

The rangelands of Gobi Gurvan Saikhan National Conservation Park have evolved with both domestic and wild ungulate grazing for thousands of years. These rangelands vary from alpine meadows to sandy deserts, but desert and semi-desert conditions dominate the region. The park's rangelands are the eastern extension of the Gobi Altai and the Mongolian word Gobi refers to both desert and desert steppe. These rangelands are dominated by low and highly variable rainfall conditions, both spatially and temporally, resulting in a non-equilibrium ecological system. The climate is continental with cold-dry winters $\left(-31^{\circ} \mathrm{F}\right)$, dry-windy springs, and hot summers $\left(104^{\circ} \mathrm{F}\right)$. In general, precipitation decreases from east to west and from north to south. At Dalanzadgad, the location of the park's headquarters, the average annual precipitation is 5.2 inches, but at Khurmen, further west and at the southern border of the park, precipitation averages only 2.2 inches. Elevation varies from approximately 3,280 to 9,300 feet and in the higher mountains of the eastern portion of the park, precipitation is greater than 8 inches. Spring (April and May) is a period of very low precipitation, high winds, and low relative air humidity. Severe dust and sand storms can develop in the early afternoon as rapid increases in temperature result in powerful air movements. These storms dry out the soil even more and inhibit early plant growth and the appearance of spring annuals. Although winter/spring precipitation is low, occasional spring snow storms can result in significant livestock losses.

As visitors of the park we saw many similarities to western U.S. rangelands, but also some very different and unique types of rangelands. Some species native to the park but introduced in the U.S. are crested wheatgrass, quackgrass, smooth brome, red fescue, Kentucky bluegrass, stinkgrass, rhubarb, lambsquarter, and fanweed. Common native species of the park and to the western U.S. include junegrass, fringed sage, common reed, and winterfat; however, there are many shared genera including Artemisia, Allium, Ephedra, Aristida, Stipa, Calamagrostis, Trisetum, Elymus, Juniperus, Kochia, Populus, and Ulmus to name only a few.

Expanses of Stipa and Allium dominate much of the park's eastern rangelands. In the
Common and scientific names of plants found in the U.S. and Gobi Gurvan National Conservation Park.
Crested wheatgrass

Junegrass

Quackgrass

Smooth brome

Red fescue

Stinkgrass

Common reed

Rhubarb

Lambsquarter

Fanweed

Fringed sage

Winterfat
Kentucky bluegrass
Agropyron cristatum

Koeleria cristata

Agropyron repens

Bromus inermis

Poa pratensis

Eragrostis minor

Phragmites communis

Rheum nanum

Chenopodium album

Thlaspi arvense

Artemisia frigida

Krascheninnikovia ceratoides
Festuca rubra

south and west, semi-desert shrub and desert shrub are more prevalent. Dry streambeds, desert pavement, rock outcrops, canyons, sand dunes, and mountains break the topography throughout the park. The diversity of land forms and vegetation support diverse wildlife populations and the nomadic lifestyles of the herding families. For this paper we have separated the vegetation of the park into 3 broad categories: montane, semi-desert, and desert.

\section{Montane Rangelands}

The montane rangelands, dominated by mountain steppe with smaller areas of alpine vegetation, wet meadows, "dwarf forests", and submontane, are the most productive rangelands within the park. These areas receive intense livestock use, especially in the summer, but many of these areas also receive winter, spring, and fall use. The mountain steppe is found on finer textured soils at elevations above 6,500 feet. Crested wheatgrass, Stipa krylovii, Festuca lenensis, Poa attenuata, junegrass, and Carex pediformis are common graminoids. Several Artemisia species, especially fringed sage, are quite common and increase on heavily grazed sites. Other common herbaceous species include Allium bidentatum, Arenaria cap illaries, Bupleurum bicaule, Hedysarum pumilum, Iris

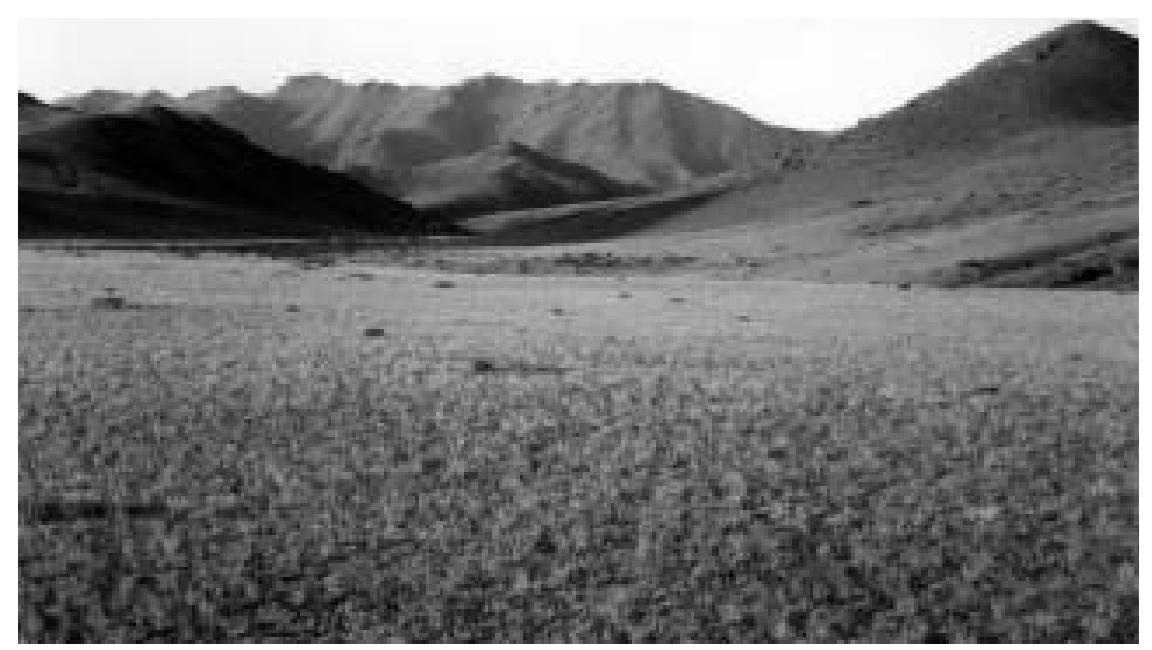

Montane grassland in Zunn Saikhan (East Beauties) Mountain Range. 


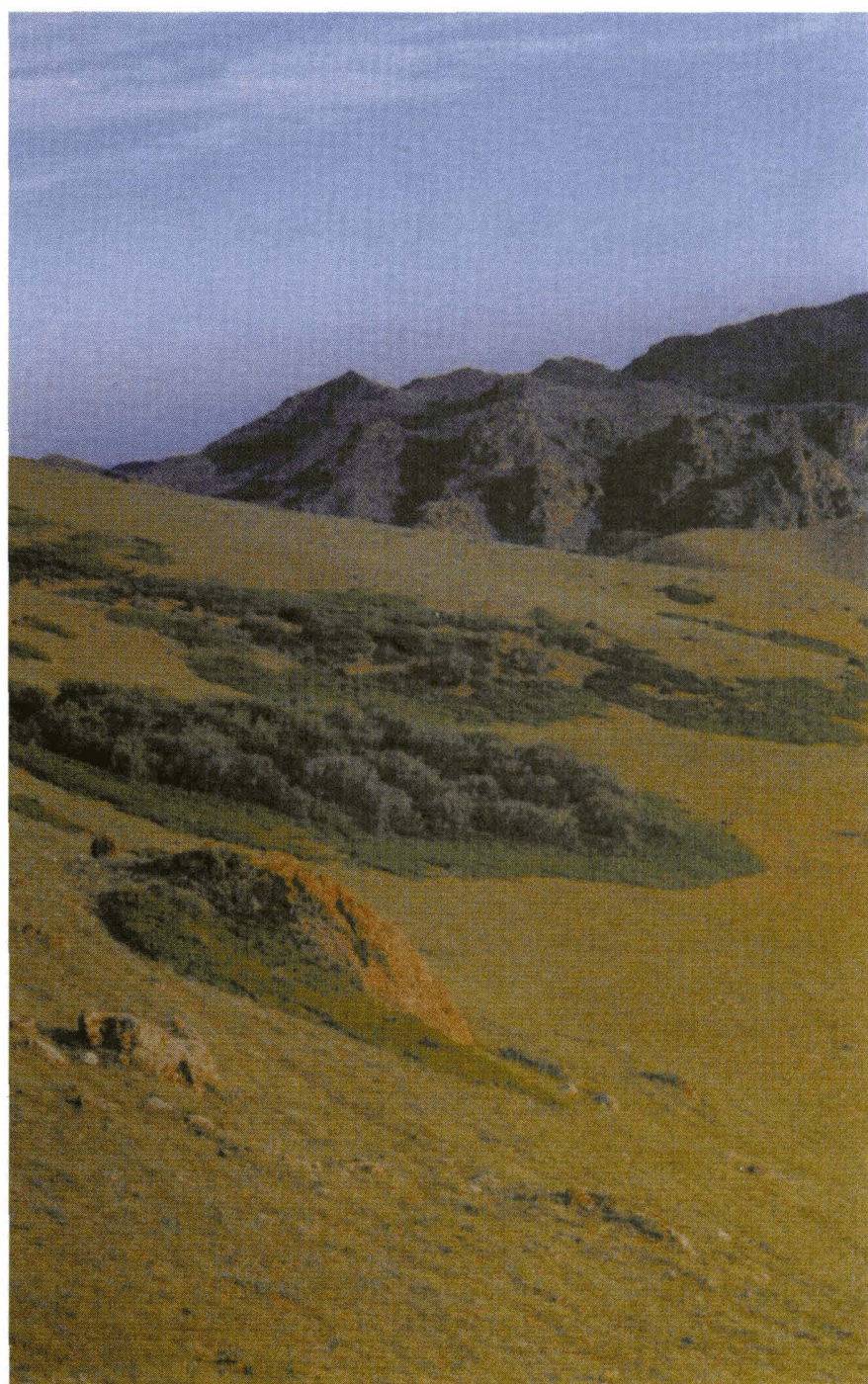

“Dwarf forest” type in montane rangelands.

potaninii, Pedicularis flava, Ptilotrichum canescens, Potentilla sericea and Sibbaldianthe adpressa. On more southern aspects or drier sites, half-shrubs become a more common community component.

Many high elevation, northern aspects or protected sites have areas of wet alpine meadows, dwarf forests, and low shrub formations. The rich alpine meadows are dominated by Kobresia species with a rich herbaceous component including Polygonum spp., Ranunculus sp, and Gentiana spp. The dominants, Kobresia sibirica and K. mysouroides, and other alpine-sedge species are utilized by grazing animals, especially yak. A dwarf forest type, consisting of subalpine birch and willow up to 15 feet high, occurs as isolated stands mostly in Dzun Saikhan. These birch/willow forests have a large component of shrubs such as Lonicera, Spirea, Cotoneaster, Ribes, Grossularia, and Rosa that are more characteristic of a boreal type than of the Gobi. These areas are surrounded by mountain steppe and are probably a relic of much cooler, wetter conditions.

A low-growing shrub type found in all mountains of the park is formed by two dwarf junipers ( $<2$ feet), Juniperus sabina and J.pseudosabina. J. sabina is considered a rare species but it is common in the park. Since it is often collected for fuel there is concern about its status. These dwarf juniper types are found at lower elevations in montane zones on north slopes or as "pockets" in protected sites. At higher elevations this type is found on all exposures where there is some protection from winds, typically on coarser soils, rocky areas, and slopes. These juniper shrub types protect many palatable plants from overgrazing and often the only grass seed-heads observed are in these areas.

In submontane zones Caragana spp., winterfat, and Amygdalus are common on coarser soils and rocky slopes. Two species of Amygadalus, A. mongolia and A. pedunculata, are common on rocky areas and along many dry water courses. These shrubs, related to our apricot, produce a small fruit that is eaten by many wild animals. Two unique and widely distributed grasses from the submontane to the semidesert are Stipa inebrians and Stipa splendens. Stipa inebrians is poisonous, according to the herders. Livestock avoid this species and often it is the dominant plant near sites of livestock concentration such as gers (the herders round felt, tent), where there are increased nutrient loads from livestock urine and feces.

\section{Semi-Desert Rangelands}

The major portion of the Gobi Altai region is semi-desert. Productivity is relatively low in this zone and drought is frequent, but this range type supplies a significant amount of the forage for the park's domestic livestock. Semi-desert rangelands of the park are dominated by desert-steppe, but significant areas of semi-desert shrub occur in many areas. The desert-steppe zone supplies forage for cattle, horses, camels, sheep, and goats, but flexibility in management is critical in this zone. The main plant forms in the desert-steppe are low caespitose grasses (Stipa gobica, S. glareosa, Cleistogenes soongarica) and Allium species (predominately $A$. polyrrhizum and A. mongolicum). Shrubs and half-shrubs such as Caragana spp., winterfat, Anabasis breviloia, and forbs such as Ajania achilleoides and Convolvulus ammanii are common, but generally of minor coverage. Twelve species of Allium have been identified in the park, and these species often provide considerable forage. These Allium rangelands

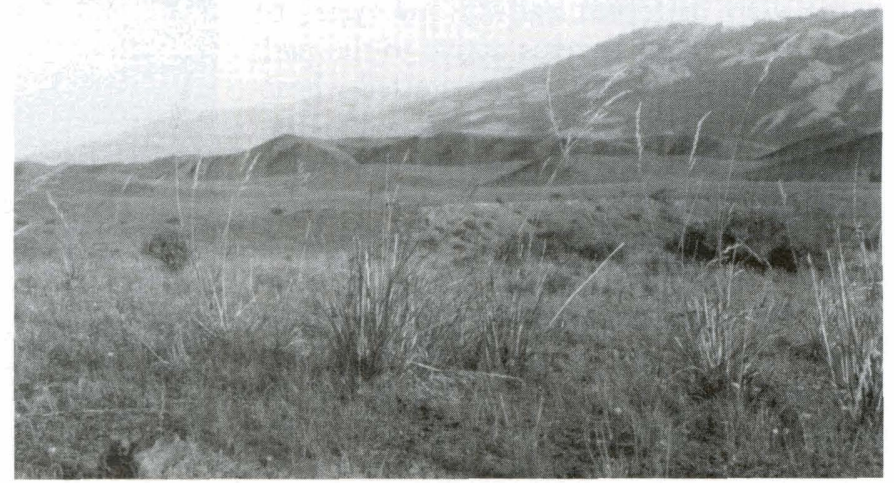

Stipa splendens (splendengrass) in submontane steppe. 
are generally quite simple floristically and we were told that livestock only use the Allium in early spring and fall because at other times it is too "hot" for the animals.

Semi-shrub desert communities are also a significant grazing resource and the shrubs are often a significant source of fuel. Important semi-desert shrub dominants include Caragana leucophloeae, winterfat, Amygdalus pedunculata, Atraphaxis pungens, Zygophyllum xanthoxylon, Potaninia mongolica and Calligonum mongolicum. Often these communities have a sparse to moderate herbaceous component, commonly with Stipa and Allium. These shrub communities are an especially important resource in the winter and during droughts, when other plants are not available or have low forage quality.

\section{Desert}

Desert dominates much of the western one-third of the park. The majority of the desert vegetation is a desert-shrub type that is dominated by shrubs and half-shrubs mostly in the Chenopodiaceae, Polygonaceae, Zygophyllaceae, and Tamaricaceae families. In general, rocky desert terrain dominates, but there are also large expanses of sand, including active sand dunes that are quite spectacular because of their size. Halophytic shrubs such as Salsola passerina, Anabasis brevi folia, ephedran (Ephedra spp.), Nitraria sibirica, Reaumuria soongorica, and Kalidium gracile are common on salty areas and are quite succulent. On stabilized sandy soils and some lower slopes and basins, saxaul (Haloxylon ammodendron) "forests" are unique. These shrubs can be over 10 feet high, which provides the desert with an unusual tall shrub component in a very xeric area. The "forests" also occur in many semiarid zones and are important because they protect fragile soils from erosion and arrest sand movement. Populus diversi folia and Elaeagnus moorcottii are found on non-saline water courses or oases.

There is little doubt that firewood gathering is a serious threat to these plant communities. Overgrazing and roads that accelerate soil erosion will likely harm these important communities. Herders utilized these desert rangelands to raise camels, goats, sheep and horses, but use of these areas is greatly limited by water availability. Localized thunderstorms and "wet years" make seasonal grazing possible.

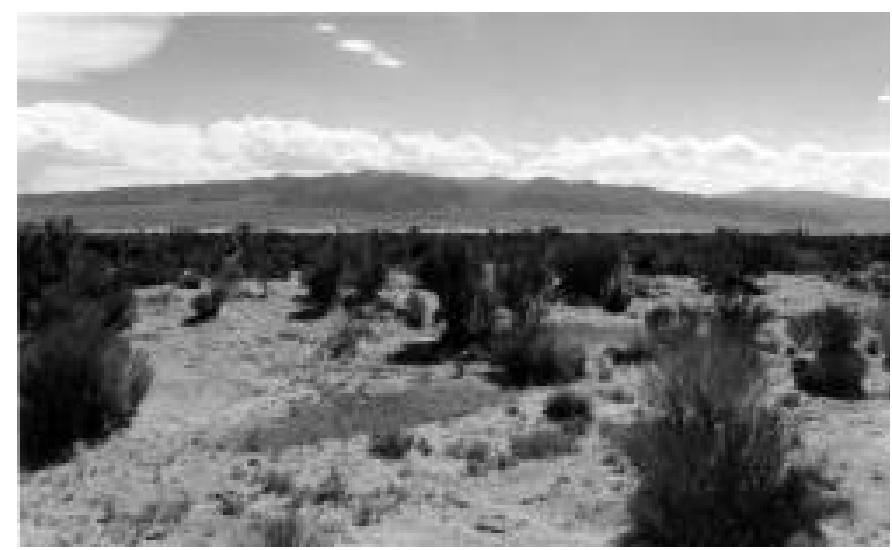

Saxaul (Haloxylon ammodendron) stand in sandy desert.

\section{Wildlife}

Gobi Gurvan Saikhan National Conservation Park is rich in wildlife and many of the wildlife populations are among the largest remaining in Mongolia. Certainly all species are important for maintaining biodiversity, but the park's large ungulates and their predators are among the most spectacular animals. There are relatively large and stable populations of Siberian ibex, Mongolian or white-tailed gazelle, and goitered or black-tailed gazelle. The ibex are often seen in the rugged mountains, on rocky outcrops, sheer cliffs, and on steep, vegetated slopes. Mongolian gazelle are found in the eastern part of the park, and goitered gazelle are in the non-mountainous areas. On one late August day, as we scanned the steppe from a small rise, we saw an unbelievable number of gazelle. Vast herds spread across the steppe as far as we could see, and our Mongolian counterparts estimated there were 10,000 gazelle.

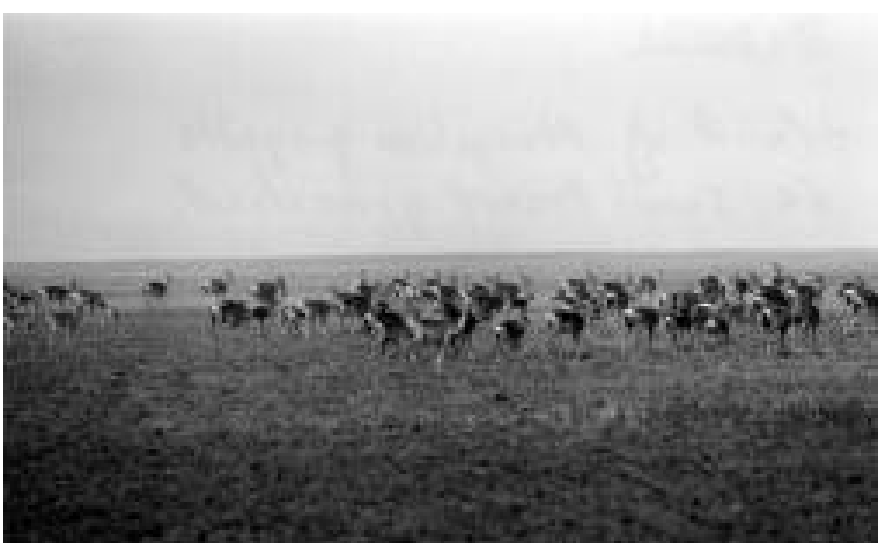

Herd of Mongolian gazelle in semi-desert grassland.

There are several globally threatened or rare species found in the park. Argali, a similar species to our bighorn except larger, is relatively common in the park but its population status is a concern. Argali are listed in the Mongolian Red Book as threatened and are included in the Appendix II of the Convention of International Trade of Endangered Species of Flora and Fauna (CITES). Most herders believe argali numbers are decreasing and there is little doubt that maintaining quality habitat for this species is a concern because of increasing livestock numbers. Argali are observed mostly along the grassy mountain slopes in the mountain steppe, but are also seen in semi-desert shrub in areas adjacent to mountain slopes.

Khulan, or Asiatic wild ass another CITES species, are seen in semi-desert and desert areas of the park, but population numbers are considered low and their use of the park is mostly seasonal. Occasional use of the western portions of the park by wild Bactrian camels and Gobi bears, both critically endangered species, have been reported, and small populations of wild boar are found in Phragmites marshes of the Zulganain River in the far western portion of the park areas.

Two species of note that have been lost from the park during the $20^{\text {th }}$ century are Przewalski's wild horse, or Takhi, and Asiatic wapiti, or elk. Przewalski's wild horse was once an inhabitant of the park and if re-introductions are successful in other parts of Mongolia it would be exciting to see a return of 
this species to the park. In Owen Lattimore's book, Mongol Journeys (1975 preface, reprint of 1941 edition), he describes a trip to the "Three Beauties of the Gobi" and mentions seeing elk. Elk do not presently occur in the park, except as pictographs, and it is difficult to determine when elk were exterminated from the area.

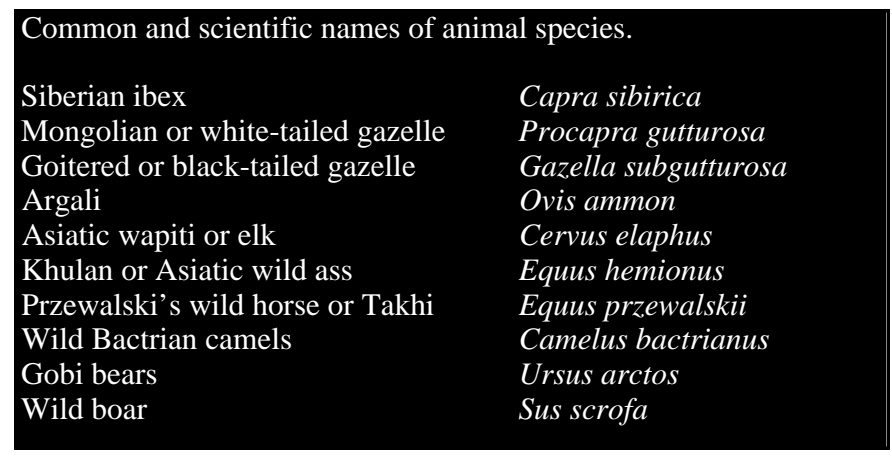

Important large predators include snow leopards, found in the mountains, and wolves, reported as relatively common throughout the park. Little is known about these predator populations, but herders often mentioned significant predation problems, mostly by wolves. Many herders reported wolves are "rampant" and cause large losses; other herders said if livestock are herded well, only minor losses occur. It is worth noting that predation by wolves is an ancient problem for Mongolian herders and Haslund, a Danish expedition member to Mongolia in the late 1920s, commented on the aggressiveness of Mongolia's wolves:

"Then there were the audacious wolves, the Mongols' hereditary foes, whose acquaintance we were forced to make. One day they took a big heifer only six hundred yards from the tent where the cowhands lived. Another time the wolves attacked our flock of sheep in broad daylight. The boy and girl who herded the sheep howled and yelled, and the sheep scattered in every direction, but in a few minutes five sheep were bitten to death and three badly torn."
Total livestock numbers and total forage sheep units within Gobi Gurvan Saikhan National Conservation Park in 1996 (from the Park Management Plan).

\begin{tabular}{|lccc|}
\hline Animal Type & $\begin{array}{c}\text { Sheep Unit } \\
\text { Equivalent }\end{array}$ & Total Head & $\begin{array}{c}\text { Total Sheep } \\
\text { Forage Units }\end{array}$ \\
\hline Cattle/Yak & 6 & 6,947 & 41,682 \\
\hline Horse & 7 & 14,610 & 102,270 \\
\hline Camel & 5 & 8,239 & 41,195 \\
\hline Sheep & 1 & 47,293 & 47,293 \\
\hline Goat & 0.9 & 141,454 & 127,309 \\
\hline Total & & 218,543 & 359,750 \\
\hline
\end{tabular}

${ }^{1}$ Sheep forage units are a Mongolian measure used to express the feed requirement of one sheep per year or $805 \mathrm{lb} /$ year forage intake.

We also saw "scarecrows" on three occasions. When we asked about the scarecrows the herders told us they were used to frighten wolves. Thus, there is little doubt that snow leopards and wolves are a concern to the herders. In most cases, the predation losses were apparently considered part of herding. However, as livestock populations increase, and if wild ungulate populations decrease, there is a strong likelihood of increased conflicts between these large predators and domestic livestock.

\section{HERDERS AND LIVESTOCK}

In 1996 there were over 218,000 head of livestock in the park managed by approximately 1,100 herding families. Mongolians have a rich herding heritage of utilizing their rangelands to produce an array of livestock products for consumption and trade. They are proud of their nomadic tradition and their varied knowledge and use of different types of livestock. Herders within the park generally have 3 to 5 types of livestock and the animals are not only a source of food, but also personal capital and a barometer of social status. Almost

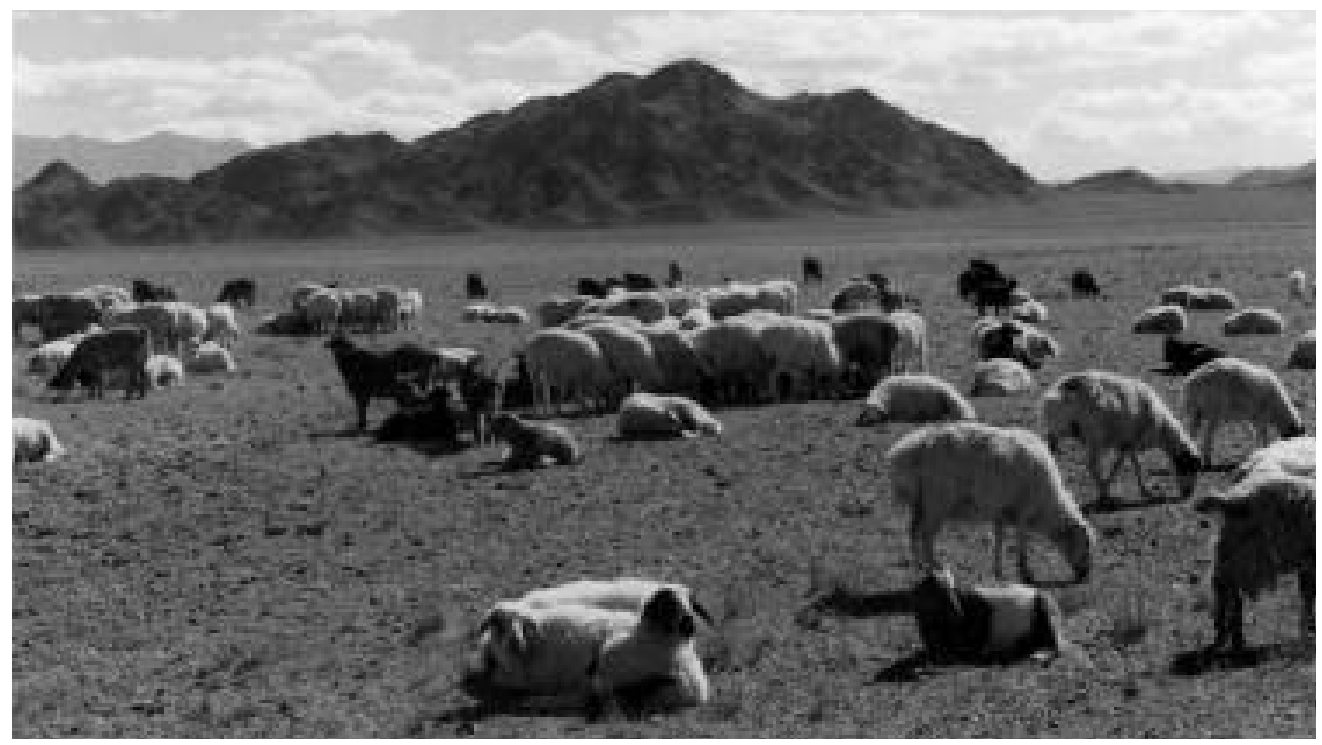

Mongolian fat-tailed sheep and goats in semi-desert grassland. 
all Mongolian herding families have horses, and certainly the Mongolian horse is famous as a riding animal, but horses here also produce dairy products (for example, the national drink "arak" or fermented mare's milk), their hair is collected for various products, and their meat is sometimes consumed.

Most herders in the park also raise sheep and goats of several breeds. The sheep breeds are of the fat-tailed sheep, a sheep that has a broad, flat tail which enlarges with fat as grazing conditions improve. The tail is considered a delicacy by Mongolians. Sheep provide meat, milk, hides, and wool. The wool is sold or bartered and is also used in the park to produce the felt for the ger (herders'round tent). Goats produce milk, meat, hides, and cashmere. The cashmere is an extremely important product for herders within the park because there is a good market for cashmere.

Cattle and camels are relatively common throughout the park, but cattle are more common in the east and camels are more common in the west. The camels are the two humped Bactrian camel that can endure extreme heat and cold. Camel meat, milk, hair, and hides are utilized, but the camel is most significant as a draft animal. The hair combed from the camel wool is a high quality fiber utilized in clothing and in blankets. The cattle are primarily native breeds, small compared to our breeds, but well adapted to the local environment. Yaks, which Mongolians include as cattle, are common at higher elevations, especially in the east. Cattle and yak are utilized as dairy, meat, and draft animals, and their hair and hides are utilized for many products such as coats, blankets, and ropes.

Although Mongolian herders use animals for meat, fiber, milk, and work, and these livestock products have been an important part of the culture and economy of Mongolia for a very long time, herders often express a dislike for killing and trading animals. They believe their animals deserve respect for what they give to the household and to merely maximize output is conventionally regarded as immoral. Thus, many Western concepts regarding livestock production become difficult to apply to the Mongolian herder who has a much different paradigm regarding the value and benefits of having livestock. Certainly Mongolians have a different perspective on risks, slaughter, and use of livestock products compared to Western cultures. These large differences in paradigms between our Western extensive system and the Mongolian system, coupled with large and significant changes in the sociopolitical system of Mongolia, certainly indicate a need for careful study and continued examination of livestock issues within the park to conserve the parks resources.

\section{Critical Issues}

A central and critical issue is how to preserve the park's resources while maintaining the pastoralist's culture. Of great concern are the increased numbers of herders and livestock in the park and lifestyle changes of many herders which affects

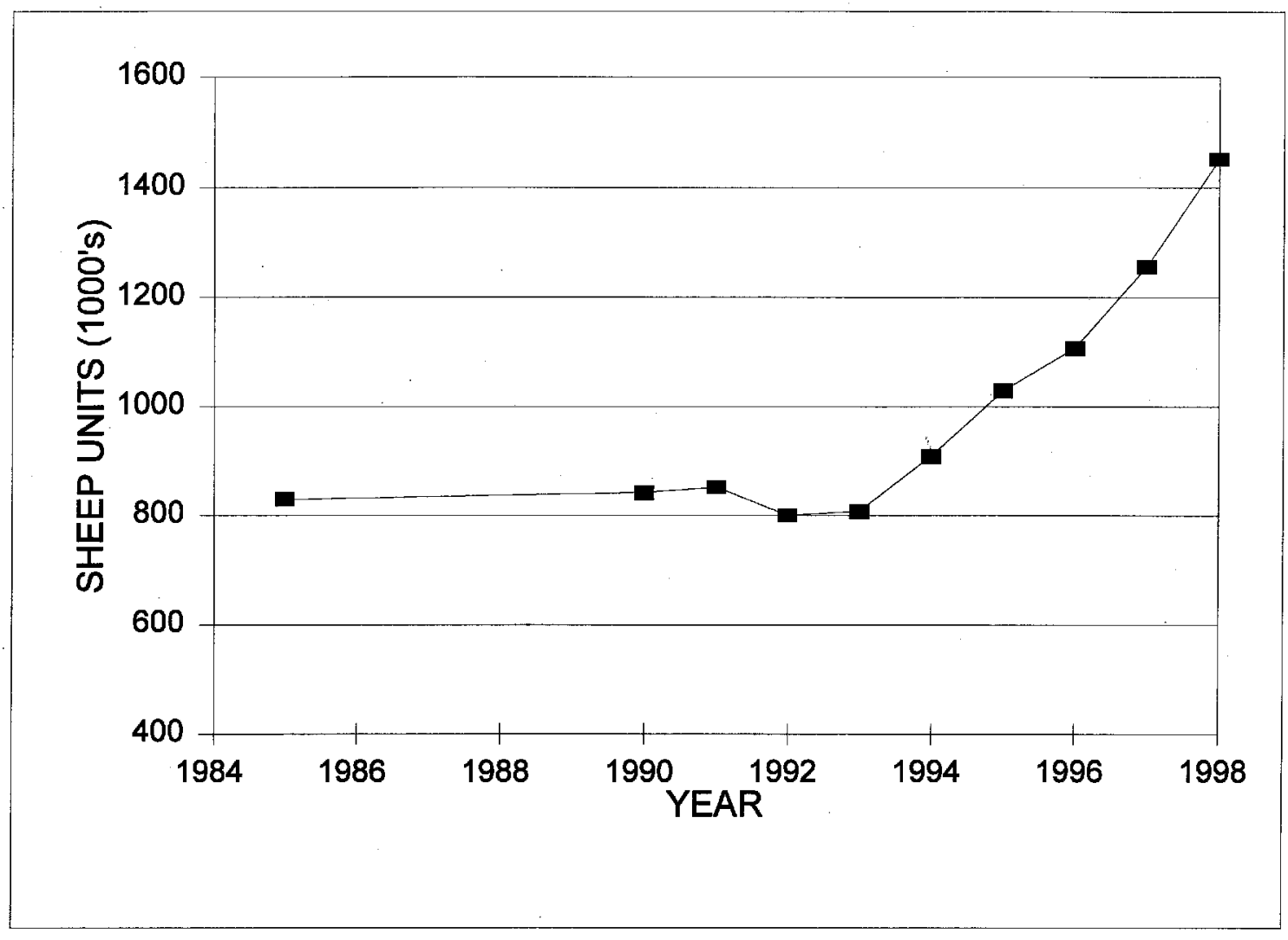

Sheep units ${ }^{1}$ for sums (Bayandalai, Bulgan, Gurvantes, Sevrei, Khanghongor, Khurmen, and Dalanzadgad) located within Gobi Gurvan Saikhan National Conservation Park.

${ }^{1}$ Sheep units are a Mongolian measure used to express the feed requirement of one sheep per year or $365 \mathrm{~kg} / y e a r$ forage intake. Accordingly, horses, cattle, camels and goats have been assigned as equivalent to 7, 6, 5 and 0.9 sheep units, respectively. 
the management of livestock. No doubt the change from a Soviet command economy to a market economy following the collapse of socialism has had a profound influence on the pastoralists of Mongolia. In the park, and apparently in many parts of the country, there has been a shift from urban to rural existence which has increased the number of people using the park's grazing lands. It is difficult to predict how Mongolia's economic transition will continue to affect the park's users. However, current trends are of concern. Since 1992, the year when most livestock negdels (collectives) were disbanded and livestock were privatized, livestock numbers have increased dramatically. Livestock numbers in the park were available only for 1996, but livestock numbers for the Omnogobi aimag and sheep units for those sums (administrative unit similar to a county) located in the park reveal an obvious increasing trend. Between 1990-93 there was a slight decrease in livestock numbers for the aimag, probably associated with changes in the socio-political system. For the aimag and the park sums there has been a $13 \%$ and $12 \%$ increase annually in total livestock and sheep units, respectively since 1993.

Another concern is the increasing number of herding families. Since 1992 the number of herders in those sums located partially in the park increased by $25 \%$. This increase is largely associated with few other opportunities for making a living, thus resulting in a change from urban to rural existence. Limiting herders use of the park could significantly affect their livelihoods. Certainly, with the increase in the number of herding families there will be increased resource use on the rangelands of the park that may detrimentally affect other resources. The aimag median age of 20 , with $24 \%$ of the human population between 5 to 15 years old in 1996, is further evidence that human population growth will likely significantly increase resource pressures on the park's rangelands if other employment opportunities are not available.

Pastoralism evolved in Mongolia largely in response to environmental factors. In the Gobi, mobility and flexible grazing allow for less risk and fewer environmental problems. A policy that restricts herder movements and/or increases concentration points will increase livestock induced environmental degradation. Livestock issues and problems associated with control of pastoralists utilizing the park's rangelands are critical problems facing land managers. These problems will be extremely difficult to solve. But if they are not solved, the impacts on the park's natural resources and the pastoralists using these resources could be devastating. Livestock grazing can have positive or negative influences on wildlife species, but overgrazing will no doubt result in a loss of habitat for wild ungulates and other valuable wildlife species. Changes in the ungulate populations will influence predator populations. A number of rare plant species have been identified in the park that could be negatively affected by human uses. These species, Amygadalus mongolica, Juniperus sabina, Potaninia mongolica, Incarvillea potaninii, Caryopteris mongolia, and Populus diversifolia are either utilized extensively by livestock or by herders for fuel wood or both. Without proper management, these activities may result in a significant decrease of these species.

\section{Summary}

Gobi Gurvan Saikhan National Conservation Park has an extremely varied landscape resulting in a high diversity of flowering plants and wildlife. It is also an area that has historically been utilized by nomadic herders and their livestock. The extensive livestock production system is an important current use of the park and surrounding areas and allows for the maintenance of the pastoralists' culture. Mongolia is extremely proud of its nomadic herding culture and this culture deserves respect and consideration. Extreme changes have occurred in Mongolia recently and throughout this century. The current grazing system of Mongolian pastoralists is, in general, not the type of management that would have been found at the turn of the century, nor is it the same as during more recent, collective times. Current livestock management is influenced by both old and recent cultures and will continue to change with socio-economic changes. Because of the scarcity of both money and expertise to manage the park, it is imperative that the pastoralists become active in managing the park. Identifying community groups within the park and getting resource information to the herders are difficult tasks. We believe that the herders do want to organize but may need facilitation and support. Conservation of park resources, including the pastoralists' culture, should be the priority in managing Gobi Gurvan Saikhan National Conservation Park.

\section{Supporting Literature}

Bruun, Ole. 1996. The herding household: economy and organization, pp. 65-89. In: Brunn, Ole and Ole Odgaard (eds), Mongolia in Transition. Nordic Institute of Asian Studies, Studies in Asian Topics, No. 22. Curzon Press Ltd., Richmond Surrey, Great Britain.

Goldstein, M.C. and C.M. Beall. 1994. The changing world of Mongolia's Nomads. University of California Press, Berkeley.

Haslund, Henning. 1934. Tents in Mongolia. E.P. Dutton and Co., Inc. N.Y., New York. 176 p.

Latimore, Owen. 1975. Mongol Journeys. AMS Press, New York. $324 \mathrm{p}$.

Sheehy, D. P. 1996. Sustainable livestock use of pastoral resources, p. 42-64. In: Brunn, Ole and Ole Odgaard (eds), Mongolia in Transition. Nordic Institute of Asian Studies, Studies in Asian Topics, No. 22. Curzon Press Ltd., Richmond Surrey, Great Britain.

Authors are Professor, School of Forestry, University of Montana and Advisor, Protected Area Management, GTZ, Ulanbaatar, Mongolia, respectively.

Information for much of this paper was obtained while working on the project "Nature Conservation and Bufferzone Development" under the aus pices of the Protected Area Bureau within the Ministry of Nature and Environment, and supported by GTZ (German Technical Cooperation). 